\title{
Temporal variation in reproductive success and the effects of differential parental care on the progeny of fish with demersal eggs
}

\author{
Mauricio Alain Guillen-Parra ${ }^{1}$, Luis Mendoza-Cuenca ${ }^{2}$, Víctor Rocha-Ramírez ${ }^{3}$ \\ Carlos Levi Pérez-Hernández ${ }^{2}$ \& Omar Chassin-Noria ${ }^{1}$ \\ ${ }^{1}$ Facultad de Biología, CMEB, Universidad Michoacana de San Nicolás de Hidalgo \\ Michoacán, México \\ ${ }^{2}$ Laboratorio de Ecología de la Conducta, Facultad de Biología, Universidad Michoacana \\ de San Nicolás de Hidalgo, Michoacán, México \\ ${ }^{3}$ Laboratorio de Ecología Genética y Molecular, Universidad Nacional Autónoma \\ de México, Michoacán, México \\ Corresponding author: Omar Chassin-Noria (ochassin@umich.mx)
}

\begin{abstract}
A paternity test based on microsatellite analysis of eggs under the parental care of a bourgeois male Pacific sergeant major, Abudefduf troschelii, included gametes from five females and two parasitic males. The nest area was monitored for five days to evaluate variation in reproductive success, and an approximately $300 \%$ increase occurred on the first and second days after new oviposition followed by a more than $300 \%$ reduction from the second to fifth days due to predation or filial cannibalism. Finally, the egg area on the last day corresponded to the initial nest area, suggesting selective care by the male.
\end{abstract}

Keywords: Abudefduf troschelii; alternative reproductive tactics; bourgeois male; parasitic males; microsatellites

Mating success expressed as the number of pairings during a season or reproductive event, and reproductive success, which depends on the size of the progeny, are fundamental components of individual fitness (Howard, 1979). Mating success is usually determined through behavioral observations or molecular analyses in fish with demersal nests that are defended by bourgeois males ("bourgeois males invest either in direct defense of mates, in monopolizing resources that are important to females or in displaying traits that attract females because they signal male quality" Taborsky, 2001). Reproductive success is based on estimating the number of gametes associated with the substrate area occupied by a nest as well as the presence and effectiveness of parental care until hatching.

In the tropical eastern Pacific, fish species of the Pomacentridae family are resident on rocky or coral reefs; they present territorial behavior, at least during the reproductive season, and males always care for fertilized demersal eggs until hatching (Fishelson,
1970). In the Pacific sergeant major, Abudefduf troschelii (Gill, 1862), a species with no sexual dimorphism, males establish a territory that is cleaned by biting the substrate and fanning it with their fins (Hernández, 2008). Once the territory is clean, males court females with rhythmic swimming and turns; the attracted female enters the territory to spawn and is followed by the male, who fertilizes the eggs (Albrecht, 1968). The bourgeois male is responsible for parental care, which involves oxygenating and cleaning the eggs with fin movements and preventing predation of the progeny as well as chasing other males that attempt to fertilize the eggs (Hernández, 2008).

Faced with this territorial behavior, some males in the population execute alternative reproduction tactics (ARTs), thus maximizing their fitness without establishing territories or performing parental care (Taborsky et al., 2008). ARTs are presented when smaller size parasitic males ("parasitic males exploit the reproductive investment of bourgeois males by beha-

Corresponding editor: Enrique Dupré 
ving quickly or inconspicuously to break the monopolization of mates by bourgeois males" Taborsky, 2001) or with lower-quality territories, i.e., lower status, "choose" (Gross, 1996) to find alternative ways to fertilize eggs in a higher-status male territory. In the genus Abudefduf, male parasites of A. abdominalis (Tyler, 1995) and A. saxatilis (Albrecht, 1968) have been observed to fertilize eggs guarded by the bourgeois males furtively.

The present study aimed to evaluate temporal variation in reproductive success and the effect of differential parental care over the progeny, assessed by behavioral observations and microsatellite analysis of progeny, to establish the number males and females that participate as gamete donors.

The territory of a bourgeois male A. troschelii and its reproductive activity were monitored for five days, from territory establishment and first spawning (September 30, 2016) to the hatching of the eggs and territory abandonment by the male (October 4, 2016), on an artificial reef (La Paz, Baja California Sur, Mexico, 240' $\left.20^{\prime \prime} \mathrm{N}, 110^{\circ} 19^{\prime} 26^{\prime \prime} \mathrm{W}\right)$. Behavioral observations of the bourgeois male were recorded daily at approximately 10:00 am for 30-60 min, and photographs of the nest with a size reference were taken daily to estimate the variation in the nest area during the entire period using ImageJ software (Schneider et al., 2012). On nesting period day four (October 3, 2016), when eggs were close to hatching, a sample was taken from the nest at a site that presented eggs from the first day, and the eggs were preserved in absolute ethanol.

The DNA of 31 eggs was obtained using the FitzSimmons (1997) protocol; three microsatellite loci were amplified by PCR (Absa 10, Absa 23, and Absa 41: Piñeros et al., 2015). The products were subjected to capillary electrophoresis using LIZ-500 as a marker, and the genotypes were determined with Peak Scanner v.1.0 (Applied Biosystems) (Fig. 1). Micro-Checker 2.2.3 (Van Oosterhout et al., 2004) was used to verify that the obtained genotypes did not present null alleles or genotyping errors. Finally, GERUD 2.0 (Jones, 2005) was used to determine the number of females and males that contributed gametes to the progeny of the nest of the bourgeois male.

Our paternity analysis showed that five different females oviposited the 31 analyzed eggs. Of these, 17 $(55 \%)$ were the progeny of the bourgeois male and the five females, while two parasitic males fertilized the remaining $14(45 \%)$. Male parasite 1 fertilised 10 eggs belonging to three females $(\mathrm{F} 1=4, \mathrm{~F} 2=3, \mathrm{~F} 3=3)$, and male parasite 2 only fertilised four eggs from two females $(F 3=2, F 4=2)$. This result evidences the existence of polygyny associated with the female's preference for the bourgeois male and nonselective polyandry associated with the ARTs of the two parasitic males.

The photographs of the nest area allowed its temporal variation to be detailed, which was associated with oviposition events and loss of eggs by predation or filial cannibalism. The area on day one was $144.1 \mathrm{~cm}^{2}$, and that on day two was $421.4 \mathrm{~cm}^{2}$, representing an approximately three-fold increase in the area associated with new oviposition. After day two, the nest markedly decreased in size; on day three, it measured $371.5 \mathrm{~cm}^{2}$, on day four, $152.1 \mathrm{~cm}^{2}$, and on day five, $135.2 \mathrm{~cm}^{2}$ (Fig. 2).

The obtained results are the first molecular evidence of a high level of paternal loss for an A. troschelii bourgeois male $(\mathrm{ca} .45 \%)$ with the contribution of gametes of two male parasites in a nest. The results also support the behavioral observations by Tyler (1995) and Albrecht (1968), which suggested the existence of "sneaking" (sensu Rowher, 1978) in A. abdominalis and $A$. saxatilis, respectively. By analyzing the recordings over the five days (236 total min), cleaning and preparation of the territory by biting the substrate were observed on day one (September 30, 2016). Then, three interactions between the bourgeois male and females were observed that resulted in three spawnings on day two (October $1^{\text {st }}, 2016$ ); the main aggressive behaviors associated with parental care were also increased on that day, including chasing and unfolding of the dorsal fin as well as fanning and buccal aeration to keep the eggs oxygenated.

The recordings did not register parasitic males, possibly due to behavior similar to that reported in $A$. saxatilis, a species in which parasitic males do not interrupt the spawning of the bourgeois male but only approach the nest to release sperm (Albrecht, 1968). However, it is possible that our results not be due to parasitic males performing ARTs. Considering that the analyzed nest was within several simultaneously active bourgeois male nest neighborhoods, at less than onemeter distance, our results may be due to bourgeois males' accidental or collateral fertilization due to male gametes transportation by water currents, evidence of the cost associated with the formation of breeding colonies (Tyler, 1995). However, this cost is compensated by shared parental care because attacks on one male by predators have a positive impact by alerting neighboring bourgeois males (Taborsky, 2001; Díaz-Muñoz et al., 2014).

The significant increase in the nest area on the second day, during which the size practically tripled, can be explained by the presence of eggs making a nest more attractive to females (Ridley \& Rechten, 1981). Alternatively, it has been suggested that the eggs on the first day, maybe "test eggs" (Manica, 2010). The number 


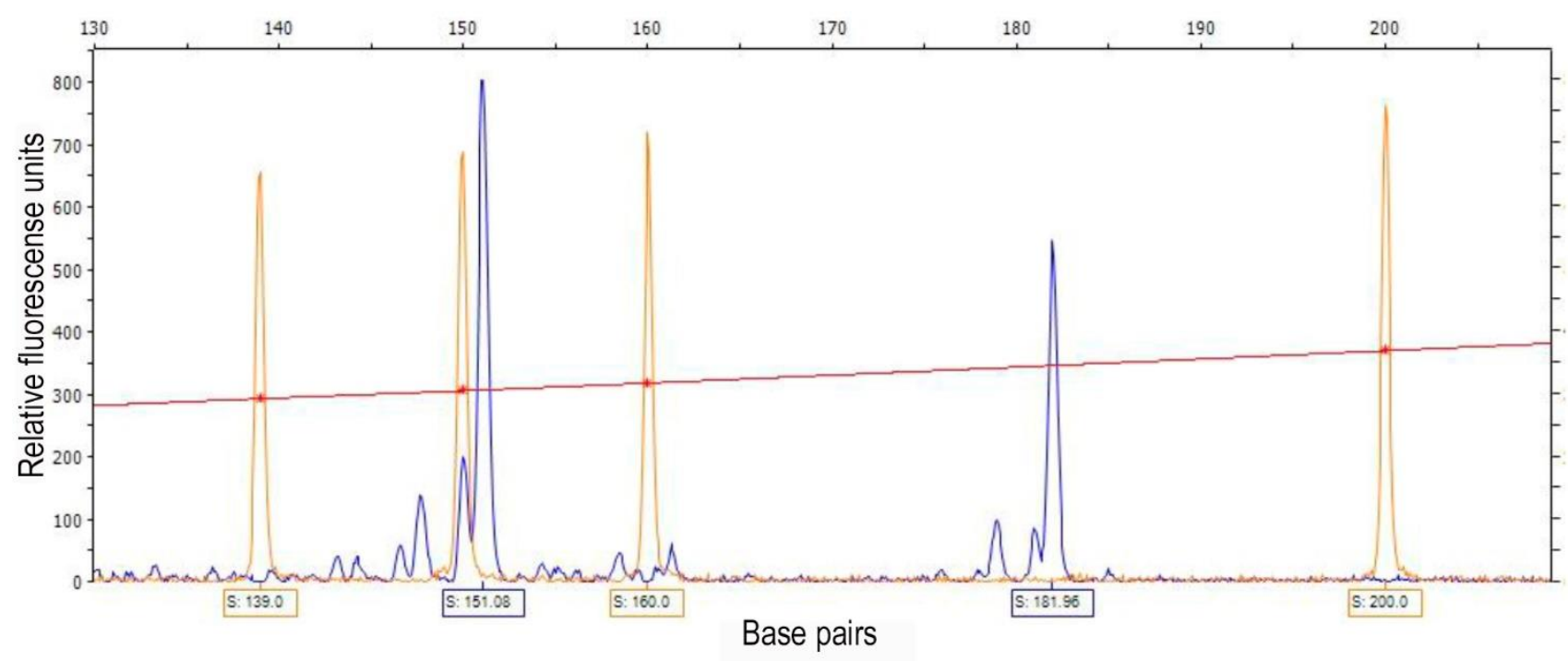

Figure 1. Electropherogram with the LIZ-500 marker (Applied Biosystems) shown by orange peaks and the Absa 23 locus shown in blue for the paternity tests; the number on the label of each peak shows the size in base pairs of the fragments.
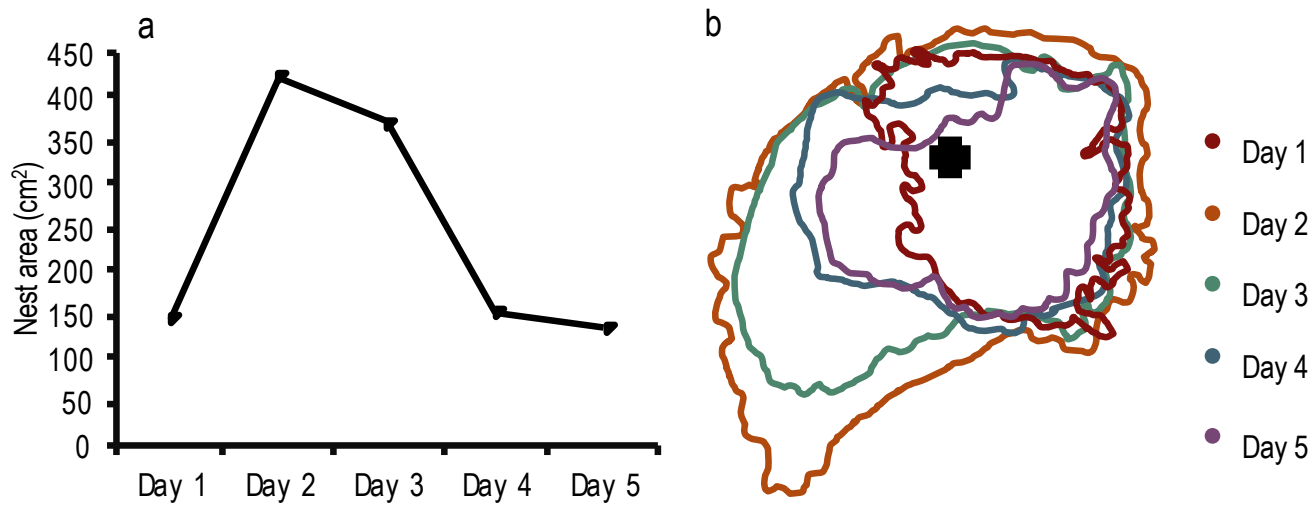

Figure 2. Abudefduf troschelii a) variation in the area, and b) contour of the nest over the five days of monitoring; the black cross represents the site where the egg sample was taken.

of these eggs that survive to the second day is an indicator of the quality of paternal care by the bourgeois male and determines whether the same females return to oviposit in the nest. However, the constant reduction in the size of the egg patch after the second day was probably due to predation both by organisms of the same species and other species and possibly filial cannibalism, a behavior that has been reported in $A$. sexfasciatus and reduces progeny by $13 \%$ (Manica, 2004). In our recordings, we detected intra- and interspecific predation of the progeny but not filial cannibalism by the bourgeois male guarding the nest.

The results illustrate the great reproductive complexity of the nests of male $A$. troschelii, suggesting that the mating and reproductive success of a bourgeois male are dynamic; thus, estimating reproductive success without considering the factors associated with this variation may generate incorrect conclusions (Hernández, 2008; Ayala, 2012). It is important to determine the age in days of male nests when analyzing progeny size to be able to compare and understand the factors that determine reproductive success. It is further suggested that it is necessary to monitor the entire nesting period from spawning to the hatching of the larvae in studies evaluating the reproductive success of fish with demersal eggs.

The diagram of the daily variation in the nest area over the five days (Fig. 1b) demonstrates that the space occupied by the nest on day one is partially included in the area presenting eggs on day five. Therefore, most of the eggs that were placed outside the original patch of eggs on day one were lost by predation on day two, providing evidence, for the first time, that the bourgeois male does not offer the same level of parental care over 
the entire egg patch. In this case, the highest quality paternal care was performed in the area of the nest that received eggs on the first day of nesting, which may be associated with differential selection of the eggs of the females that spawned on day one, which are possible of higher quality. These results suggest that most of the eggs obtained on the second day are bred from lowerquality females or, as they require the male to care for the nest one day longer, are less protected from predation or are preferred for filial cannibalism.

\section{ACKNOWLEDGMENTS}

The authors thank the National Laboratory of Ecological Analysis and Synthesis (LANASE, www.lanase. unam.mx) for supporting the molecular analysis. This study was funded by the Coordination of Scientific Research, Universidad Michoacana de San Nicolás de Hidalgo (UMSNH), and by a grant from CONACyTUNAM-UAGro-UMSH-LANASE (2015-250996 and 2016-271449 and 2017-280505). All specimens were collected under national legislation and transported to the Fish Collection of the Facultad de Biología (CPUM), UMSNH, under Scientific Collection Registry MICH.PEC-227-07-09.

\section{REFERENCES}

Albrecht, H. 1968. Behavior of four species of Atlantic damselfishes from Columbia, South America, (Abudefduf saxatiles, A. taurus, Chromis multilineata, C. cyanea; Pisces, Pomacentridae). Institute of Marine Science, Miami, 969: 662-676.

Ayala, J.A. 2012. Elementos de dinámica poblacional para el manejo de peces damisela del Golfo de California, México. Thesis, Universidad Autónoma de Baja California Sur, B.C.S. [http://biblio.uabcs.mx/tesis/ TE\%202736.pdf]. Reviewed: September 7, 2018.

Díaz-Muñoz, S.L., DuVal, E.H., Krakauer, A.H. \& Lacey, E.A. 2014. Cooperating to compete: altruism, sexual selection, and causes of male reproductive cooperation. Animal Behaviour, 88: 67-78.

Fishelson, L. 1970. Behaviour and ecology of a population of Abudefduf saxatilis (Pomacentridae, Teleostei) at Eilat (Red Sea). Animal Behaviour, 18: 225-237.

FitzSimmons, N., Moritz, C. \& Moore, S.S. 1995. Conservation and dynamics of microsatellite loci over 300 million years of marine turtle evolution. Molecular Biology and Evolution, 12: 432-440.

Received: 6 March 2019; Accepted: 6 March 2020
Gross, M.R. 1996. Alternative reproductive strategies and tactics: diversity within sexes. Trends in Ecology \& Evolution, 11: 92-98.

Hernández, L. 2008. Ecología reproductiva de peces de arrecife rocoso en el suroeste del Golfo de California, México. PhD Thesis, IPN-CICIMAR, Ciudad de México, 184 pp. [http://repositoriodigital.ipn.Mx/ handle/123456789/14201]. Reviewed: September 7, 2018.

Howard, R.D. 1979. Estimating reproductive success in natural populations. American Naturalist, 114: 221231.

Jones, A.G. 2005. GERUD 2.0: A computer program for the reconstruction of parental genotypes from half-sib progeny arrays with known or unknown parents. Molecular Ecology Resources, 5: 708-711. doi 10.1111/ j.1471-8286.2005.01029.x

Manica, A. 2004. Parental fish change their cannibalistic behaviour in response to the cost-to-benefit ratio of parental care. Animal Behaviour, 67: 1015-1021.

Manica, A. 2010. Female scissortail sergeants (Pisces: Pomacentridae) use test eggs to choose good fathers. Animal Behaviour, 79: 237-242.

Piñeros, V.J., Gutiérrez-Rodríguez, C. \& Lance, S.L. 2015. Development and characterization of 29 microsatellite markers for the sergeant major damselfish (Abudefduf saxatilis) using paired-end Illumina shotgun sequencing. Conservation Genetics Resources, 7: 103-105. doi: 10.1007 /s12686-014-0303-8

Ridley, M. \& Rechten, C. 1981. Female sticklebacks prefer to spawn with males whose nests contain eggs. Behaviour, 76: 152-161.

Rowher, S. 1978. Parent cannibalism of offspring and egg raiding as a courtship strategy. American Naturalist, 112: 429-440.

Schneider, C.A., Rasband, W.S. \& Eliceiri, K.W. 2012. $\mathrm{NIH}$ Image to ImageJ: 25 years of image analysis. Nature Methods, 9: 671-675.

Taborsky, M. 2001. The evolution of bourgeois, parasitic and cooperative reproductive behaviors in fishes. Journal of Heredity, 92: 100-110.

Taborsky, M., Oliveira, R.F. \& Brockmann, H.J. 2008. The evolution of alternative reproductive tactics: concepts and questions. In: Oliveira, R.F., Taborsky, M. \& Brockmann, H.J. (Eds.). Alternative reproductive tactics: an integrative approach. Cambridge University Press, New York, pp. 421-434.

Tyler, W.A. 1995. The adaptive significance of colonial nesting in a coral-reef fish. Animal Behaviour, 49: 949-966.

Van Oosterhout, C., Hutchinson, W.F., Wills, D.P.M. \& Shipley, P. 2004. Micro-Checker: software for identifying and correcting genotyping errors in microsatellite data. Molecular Ecology Resources, 4: 535-538. 